\title{
Friends' Support, Motivation to Learn, Emotional Adjustment, and Academic Performance among Indonesian First-Year Students
}

\author{
Theresia Indira Shanti ${ }^{* 1}$, J.M.A.M. Janssens ${ }^{2}$, Bernadette Setiadi ${ }^{3}$ \\ ${ }^{1}$ Faculty of Psychology, Atma Jaya Catholic University of Indonesia, ${ }^{2}$ Behavioral Science Institute, Radboud \\ University, Montesorilaan, ${ }^{3}$ Faculty of Psychology, Atma Jaya Catholic University of Indonesia
}

Submitted 19 March 2018 Accepted 2 October 2020 Published 30 August 2021

\begin{abstract}
First-year students face academic and social challenges which will undermine their motivation to learn and emotional adjustment. Friends' support helps them to cope which then influences their academic performance. This study aimed to investigate relations between friends' support and academic performance, as mediated by a motivation to learn and emotional adjustment. Participants were 327 first-year university students at the end of their first year, recruited from random cluster sampling. Data were analyzed using Sobel Test indicated that motivation to learn and emotional adjustment fully mediated the relationship between friendship quality and academic performance, between lack of intimacy with friends and academic performance, and between conflict with friends and academic performance. Friends provide support which enables students to have discussion to solve their difficulties in facing academic challenges and to disclose their thoughts and feelings to face their emotional challenges. We recommend that further studies collect the data from students in each year and universities to design a curriculum that promotes supportive collaboration among students.
\end{abstract}

Keywords: first-year students; friends' support; motivation to learn; emotional adjustment; academic performance

Indonesia commits to improve its education system as evident to commitment to the Sustainable Development Goals. The academic performance of higher education students is one of the indicators used by the Indonesian government to identify the quality of the education system (BAN-PT, 2019). Factors influencing students' low academic performance in their first year are academic and social challenges to adjust to their new environment (van Rooij et al., 2018). Academically, they enter a different education system from which they have experienced in high school. In university, students are are now required to carefully plan their academic pathway. Similarly, on a social aspect, students are exposed to a greater variety of individuals from different traditions and backgrounds with whom they have to work and collaborate. (Wongtongkam, 2019) found that coping with the aforementioned challenges involves an academic and social integration process, in which first-year students have to adapt to their friends and university staff's attitudes and values and become a member of the academic and social system of the university.

Many studies such as those of Ahmed et al. (2008) and Clifton et al. (2004) found associations between friends' support and students' academic performance. First-year students need support, especially from friends who are dealing with the same challenges, and therefore better understand their actual needs (Swenson et al., 2008). First-year students dealing with stress related to adjusting to university life that may undermine their emotional adjustment (Conti, 2000). Emotional adjustment is a process of interaction between an individual and his/her environment that requires a variety of coping responses in an attempt to bring emotional harmony between the demands and needs of an individual and those of his/her environment (Bohlin \& Hagekull, 2009; Ramsay et al., 2007; Rey et al., 2013)

${ }^{*}$ Address for correspondence: indira.shanti@atmajaya.ac.id 


\section{Shanti, et al || Friends' Support}

To date, there has been an attention to the study of friend support to students' motivation. However, highlight has been put in the studies about friendship were conducted in individualistic cultures, which are different to the context of Indonesia that is known for its collectivism. Scholars such as Valente2016 have expressed differences between individualistic and collectivistic cultures, particularly in the expression of seeking and giving support in friendship. People in individualistic cultures tend to think that it is the individual's responsibility to say what is in one's mind if one expects to be attended to or understood, whereas people in collectivistic cultures tend to think that providers of support tend to have the willingness and ability to feel and think what others are feeling and thinking without being told (Markus \& Kitayama, 1991).

The purpose of this study was to examine the mediating role of motivation to learn and emotional adjustment between friends' support and the academic performance of first-year university students in a collectivistic culture context such as Indonesia. The hypotheseis of this study iswere: motivation to learn mediates relationship between friendship quality and academic performance, motivation to learn mediates relationship between lack of intimacy and academic performance, motivation to learn mediates relationship between conflict with friends and academic performance, emotional adjustment mediates relationship between friendship quality and academic performance, emotional adjustment mediates relationship between lack of intimacy and academic performance, and emotional adjustment mediates the relationship between conflict of friends and academic performance among first-year university students.

\section{Literature review}

Friends' support refers to students' perception of an interpersonal process that involves actions and information that may lead them to feel that they receive help in the academic area from other students when they need it (Friedlander et al., 2007; Linden-Andersen et al., 2008). Earlier studies found evidence on the relations between friends' support and motivation (Ryan, 2001) as well as between motivation and academic performance (Clark \& Schroth, 2010; Major et al., 2006). Evidence for relationships between friends' support and emotional adjustment was also reported by (Ciairano et al., 2007; Petersen et al., 2009) found positive relations between friends' support, emotional adjustment and academic performance.

Motivation to learn can be defined as a set of interrelated beliefs and emotions that direct students' behavior to attend and learn materials presented in the academic program (Tucker et al., 2002). These beliefs include self-efficacy, that influence how the students will exert their effort to reach a particular goal because they believe they can achieve their aims. Motivation to learn directs the students' behaviors towards acquiring knowledge and behavior to be mastered and achieved (Wilson \& Madsen, 2008).

Friends' support is related to academic performance (Ryan, 2001). Friends who provide support to overcome problems including difficulties in studying, for example, by advising on how to work more efficiently and about their university's academic demands (Buote et al., 2007; Clifton et al., 2004), enable first-year students to collaborate with each other in order to resolve academic challenges (Buote et al., 2007) and integrate with the university's standards. Friends' support is related to students' motivational beliefs. Friends' information and help increase students' belief that they are competent to perform a given activity, including learning activities. These beliefs direct students' behaviors to pay attention and learn materials presented in the academic program (Tucker et al., 2002).

Friends' support is related to emotional adjustment and is an essential determinant of how individuals adjust to their new situation, particularly in stressful periods as experienced by first-year students (Buote et al., 2007). Having friends who are facing the same challenges offers encouragement (Buote et al., 2007; Ciairano et al., 2007), reduces anxiety, helps students to overcome their problems, enhances happiness (Ahmed et al., 2008), and enables them to accept the values of their university, which in turn leads to emotional adjustment (Rodriguez et al., 2003; Swenson et al., 2008). Motivation to learn is related to academic performance (Vermunt, 2005). Students with a higher motivation to learn to prioritize learning activities, exert energy in learning, persist with a learning task, and try to integrate the high academic standards of their university (Schneider et al., 2008). 


\section{Shanti, et al || Friends' Support}

Studies have shown that first-year students's academic performance is also affected by their emotional adjustment (Petersen et al., 2009). One possible explanation is that students who have better emotional adjustment tend to have characteristics such as less anxiety and greater use of active coping, which prevent them from giving up something essential and enable them to manage, decrease, or eliminate stressors or the emotional consequences of stressors they experience in adjusting to university life (Yazedjian et al., 2009). In turn, they can focus their attention and concentration on academic challenges, which leads them to integrate into their university's high standards of academic performance.

Given that friends' support is related to motivation to learn and to emotional adjustment, and that motivation to learn and emotional adjustment are related to academic performance, I assume that differences in motivation to learn and in emotional adjustment represent the mechanisms through which friends' support exerts its influence on academic performance. This assumption implies that first-year students who perceive their friends as supportive tend to show more motivation to learn and more emotional adjustment, and achieve a better academic performance than those who perceive their friends as less supportive.

\section{Method}

\section{Study Design and Participants}

Inclusion criteria of participants in this study were male and female first-year students of university $\mathrm{X}$ who were, during the research period, in their second semester. According to van Rooij et al. (2018), first-year students are vulnerable to face challenges in adjusting to their new environment. Exclusion of the criteria were university $\mathrm{X}$ students who were not first-year students and who were in classes when we collect the data.

After receiving clearance from the university research review committee to conduct this study and permission from the dean of each faculty, data were collected using cluster sampling, which is accomplished by dividing the population into faculties and then selected randomly within faculties until we reach the criterion of $20 \%$ of first-year students of each faculty. The sample included 114 $(34.9 \%)$ first-year male and $213(65.1 \%)$ female students between 17-20 years old $(\mathrm{M}=18.52, \mathrm{SD}=.67)$ from all faculties of $X$ University. $X$ University consists of 8 faculties, each of which is led by a dean. Our goal was to select $20 \%$ of first-year students of each faculty of X University.

\section{Instruments}

\section{Academic performance}

Academic Performance was measured by students' grade point average (GPA) at the end of their first year. At X University, GPA is the overall weighted sum of all grades contributing to a student's final degree (range 0 to 4 ).

2. Motivation to learn

Motivation to learn was assessed by a 10-item scale adapted from the Stages of Learning Motivation Inventory (SOLMI) developed by (Cole et al., 2004). The participants rated their agreement on a 5-point Likert scale, ranging from "strongly disagree" (1) to "strongly agree" (5). A sample item is, "I have been working hard to learn the information covered in the course/class." The SOLMI was carefully adapted and translated into the Indonesian language using the forward-back translation (ABBA) technique. Three independent translators conducted the forward-back translation in the forward-translation phase and three other independent translators in the back-translation phase. For each student, a sum score was computed over the ten items. Total scores for students ranged from 10 to 50. After the adaptation, the instrument was checked for its reliability. Cronbach's alpha was .84. 


\section{Shanti, et al || Friends' Support}

\section{Emotional adjustment}

The Emotional Adjustment Scale used in the present study the Indonesia adaptation of healthy adjustment scale (Haber \& Runyon, 1984) consisted of: accurate perception of reality (e.g., "I feel I have no purpose in life."), ability to cope with stress and anxiety (e.g., "I feel anxious."), a positive self-image (e.g., "I am satisfied with myself."), ability to express the full range of emotions (e.g., "I can express my emotions."), and good interpersonal relationships (e.g., "I can cope with the demands of the environment quite well."). Indonesian Emotional Adjustment scale consisted of 12 items and was trialled in the pilot study. Five hudred and fifty four first-year students of X University participated in the trial. The participants rated their agreement on a 4-point Likert scale, ranging from "strongly disagree" (1) to "strongly agree" (4). Cronbach's alpha was .72, indicating a good internal consistency of the scale.

The scale's construct validity was addressed in the pilot study by investigating the relationships between this scale and other scales. We hypothesized that the scale would be negatively related to reported stress, anxiety, and depression symptoms (Demaray et al., 2005). Stress, anxiety, and depression symptoms were measured by the Depression, Anxiety, Stress Scale (DASS) developed by (Lovibond \& Lovibond, 1995). DASS is increasingly used in diverse settings and possesses good psychometric properties (Crawford \& Henry, 2003). The Emotional Adjustment Scale was significantly related to the Stress Scale $(r=-.41, p<.01)$, the Anxiety Scale $(r=-.42, p<.01)$, and the Depression Scale $(r=-.52, p<.01)$. The results of the construction of The Emotional Adjustment Scale from the pilot study were used in the present study, reported in this manuscript. In the present study, Cronbach's alpha was .74, with students' total scores ranging from 12 to 48 .

4. Friends' support

The scale used in the present study to measure friends' support was developed in another pilot study. In the first step of that pilot study, we asked 183 first-year students of X University two open questions to find out the kind of support from their friends that could help them adjust and perform during their first year. The first question was about friends' behaviors that they perceived as supportive, while the second asked them to explain how these behaviors supported them. Based on their answers to these open questions, we formulated scale consists of 33 items..

In the second step of that pilot study, we distributed the scale items to 554 first-year students of $X$ University to examine the reliability and validity of the scale. In the third step of the pilot study, factor analysis was carried out to detect friends' support dimensions. This analysis revealed three factors. The first factor was dominated by high loadings ( $>.40)$ of items that expressed friendship quality and consisted of 16 items, and the second factor was dominated by high loadings of items that expressed lack of intimacy with friends and consisted of 7 items, while the third factor was dominated by high loadings of items that expressed conflict with friends and consists of 4 items.

In the fourth step of the pilot study, we constructed three scales based on the results of the third step explained above. The three scales are a Friendship Quality Scale, Intimacy Scale, and a Conflict with Friends Scale. The construct validity of these three scales was demonstrated by correlating the scales' scores with scores on variables that might have significant associations with the three scales. We hypothesized that the Friendship Quality Scale would be negatively related to reported stress, anxiety, and depression symptoms, while the Lack of Intimacy Scale and Conflict with Friends Scale would be positively related to reported stress, anxiety, and depression symptoms. DASS measured stress, anxiety, and depression symptoms. The Friendship Quality Scale was significantly related to the Anxiety Scale $(r=-.11, p<.01)$ and the Depression Scale $(r=-.25, p<.01)$, but not to the Stress Scale ( $r=-.08)$. The Lack of Intimacy Scale was significantly related to the Stress Scale $(r=.28, p<.01)$, Anxiety Scale $(r=.31, p<.01)$, and Depression Scale $(r=.40, p<.01)$. Conflict with Friends Scale was positively and significantly related to the Stress Scale $(r=.34, p<.01)$, the Anxiety Scale $(r=.32, p<.01)$, and the Depression Scale $(r=.33, p<.01)$.

In the present study, in which the data were used for this manuscript, the same scales were used. A sample item from the Friendship Quality Scale is "I have friends who help me when I have a problem," a sample item of the Lack of Intimacy Scale is "It is difficult for me to find a friend with whom I can enjoy some activities together," while a sample item of the Conflict with Friends Scale is "I still regret the conflict that I have with my friends." The participants rated their agreement on a 4-point Likert 


\section{Shanti, et al || Friends' Support}

scale, ranging from "strongly disagree" (1) to "strongly agree" (4). Cronbach's alpha was .92 for the Friendship Quality Scale with student's total scores ranging from 16 to 64, Cronbach's alpha was .79 for the Lack of Intimacy Scale with student's total scores ranging from 7 to 28, and Cronbach's alpha was .68 for the Conflict with Friends Scale with student's total scores ranging from 4 to 16.

\section{Data collection}

This study used a correlational design, specifically predictive design. In the first-year students' classrooms, the questionnaires were administered at the end of their first year at university by the primary researcher and trained research assistants (between 15 to 31 July 2013). Students were given the questionnaires approximately 30 minutes before their scheduled classes ended. A script of the study's aims, informed consent, and instructions was used to maintain consistency in the procedure. Only students who signed the informed consent form, wrote their name in the questionnaire, and gave permission to the researcher to access their GPA at the end of their first year, were allowed to participate.

Questionnaires took approximately 20 to 30 minutes to complete. The principal researcher or the trained research assistants remained in the classroom to answer any questions that students might have about the items. Participants returned the completed questionnaires to a research assistant before leaving their class. Participants received a souvenir for taking part in the study. At the end of their first year, participants' GPAs were obtained from the university database.

\section{Data analysis}

The first step is to analyze all variables being studied, that is relationship between friendship quality and academic performance, lack of intimacy and academic performance, conflict with friends and academic performance, friendship quality and motivation to learn, lack of intimacy and motivation to learn, conflict with friends and motivation to learn, friendship quality and emotional adjustment, lack of intimacy and emotional adjustment, as well as conflict with friends and emotional adjustment.

\section{Figure 1}

A model for a causal chain (Baron E Kenny, 1986)

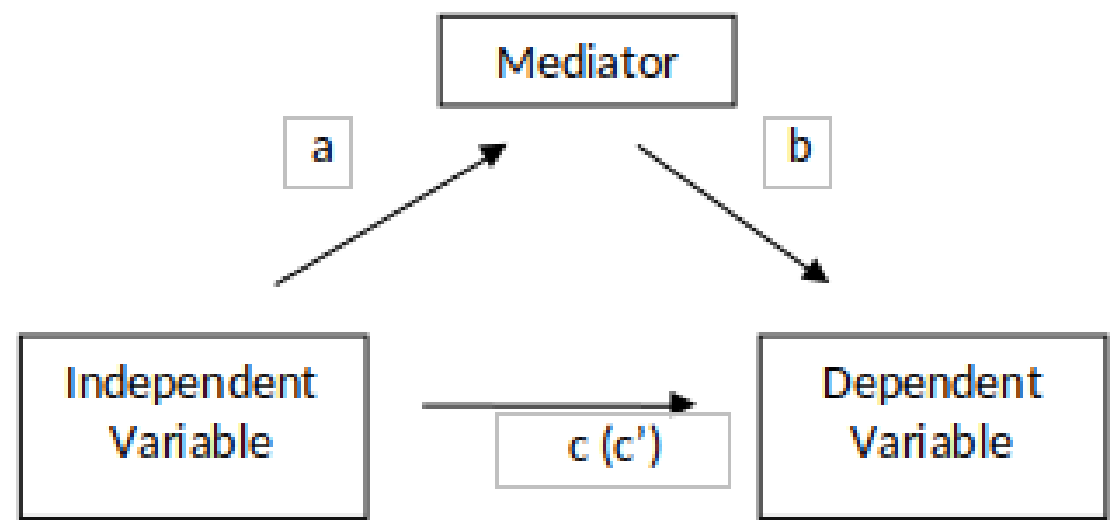

The second step is was to test the mediating role of motivation to learn and emotional adjustment. Baron and Kenny (1986) proposed a path diagram as a model for depicting a causal chain (Figure 1). In order to establish mediation, four conditions have to be fulfilled. From the regression analysis, it has to be clear that (1) the independent variable affects the mediator as diagrammed in the path a, (2) the independent variable affects the dependent variable as diagrammed in path $c_{,}(3)$ the mediator affects 


\section{Shanti, et al || Friends' Support}

the dependent variable when both the independent variable and the mediating variable are used as predictors as diagrammed in path $b$, and (4) the effect of the independent variable on the dependent variable must be less when the mediator is introduced in the regression analysis as diagrammed in path c'. Perfect or full mediation is supported if the independent variable no longer has any direct effect on the dependent variable after the inclusion of the mediator in the regression analysis (Baron \& Kenny, 1986). We tested the significance of mediation by Sobel tests.

\section{Results}

Table 1 presents correlations between all variables being studied, of which we found a positive relation between friendship quality and academic performance; a negative relation between lack of intimacy and academic performance, as well as negative relation between conflict with friends and academic performance. With regard to motivation to learn, we found a positive relation between friendship quality and motivation to learn, a negative relation between lack of intimacy and motivation to learn, and conflict with friends and motivation to learn. We also found positive correlations between friendship quality and emotional adjustment, a negative relation between lack of intimacy and emotional adjustment, and conflict with friends and emotional adjustment. Moreover, we found positive correlations between academic performance and motivation to learn and between academic performance and emotional adjustment.

Table 1

Correlations between Friends Factors, Motivation to Learn, College Adjustment, and Academic Performance

\begin{tabular}{|c|c|c|c|c|c|c|c|}
\hline & Variable & 1 & 2 & 3 & 4 & 5 & 6 \\
\hline 1. & Friendship Quality & - & $-.63^{* *}$ & $-.33^{* *}$ & $.22^{* *}$ & $.47^{* *}$ & $.16^{* *}$ \\
\hline 2. & Lack of Intimacy & & - & $.49^{* *}$ & $-.17^{* *}$ & $-.52^{* *}$ & $-.15^{* *}$ \\
\hline 3. & Conflict with Friends & & & - & $-.25^{* *}$ & $-.55^{* *}$ & $-.14^{*}$ \\
\hline 4. & Motivation to Learn & & & & - & $.32^{* *}$ & $.27^{* *}$ \\
\hline 5. & Emotional Adjustment & & & & & - & $.21^{* *}$ \\
\hline 6. & Academic Performance & & & & & & - \\
\hline
\end{tabular}

Note. ${ }^{* *} \mathrm{p}<0.01$ level (2-tailed); ${ }^{*} \mathrm{p}<0.05$ level (2-tailed)

In Table 2, 3, and 4, we present the results about the mediating role of motivation to learn between the three friend factors (friendship quality, lack of intimacy, and conflict with friends) and academic performance by examining the four Baron and Kenny's conditions that have to be met to conclude to a mediating effect. From Table 2, 3, and 4, it is clear that when the motivation to learn was included in the analyses, the standardized regression coefficient of friendship quality on academic performance was reduced from $.16^{* *}$ to .11 (see Table 2), the standardized regression coefficient of lack of intimacy on academic performance from -.15 regression coefficient of conflict with friends on academic performance from $-.14^{*}$ to -.08 (see Table 4). Sobel tests confirmed a significant full mediation of motivation to learn concerning the relationship between friendship quality and academic performance $(\mathrm{t}=3.07 ; p<.01)$, the relationship between lack of intimacy and academic performance $(\mathrm{t}=2.60 ; p<.01)$, and the relationship between conflict with friends and academic performance $(\mathrm{t}=3.22 ; p<.01)$. 


\section{Shanti, et al || Friends' Support}

Table 2

Regression Analyses Predicting Academic Performance by Friendship Quality mediated by Motivation to Learn

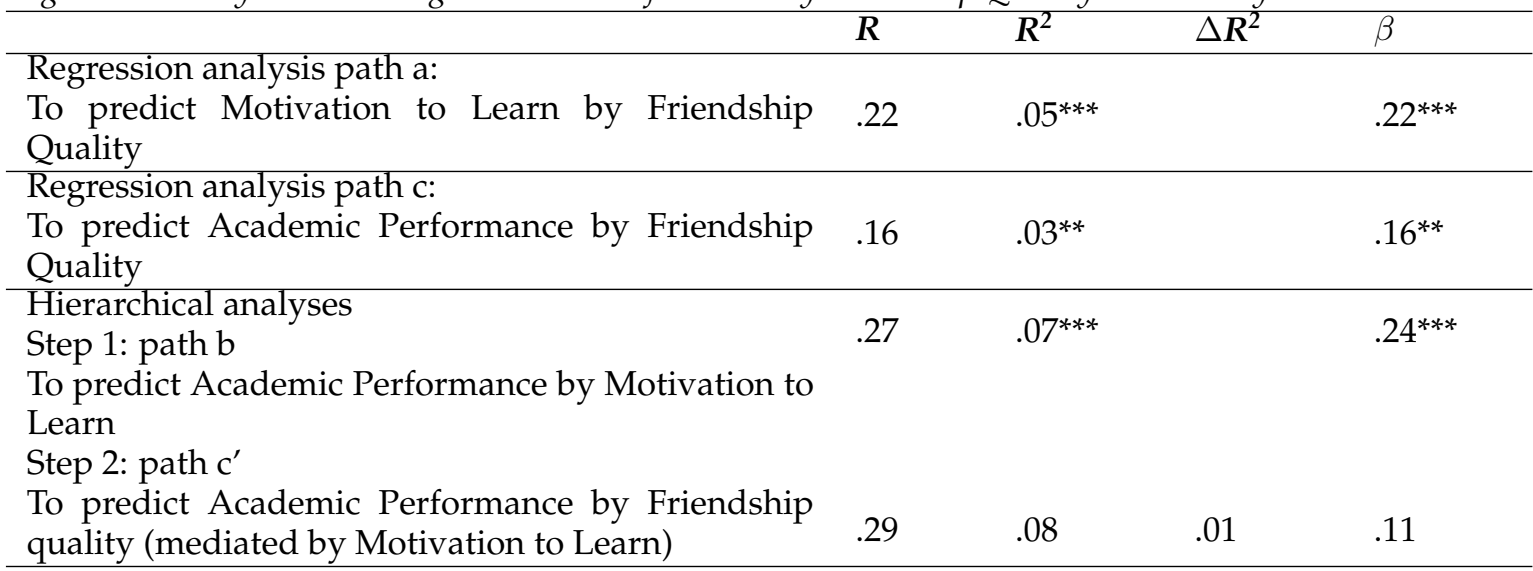

Note $^{*}=p<.05 ;{ }^{* *}=p<.01 ;=\mathrm{p}^{* * *}<.001$

Table 3

Regression Analyses Predicting Academic Performance by Lack of Intimacy mediated by Motivation to Learn

\begin{tabular}{|c|c|c|c|c|}
\hline & $R$ & $R^{2}$ & $\Delta R^{2}$ & $\beta$ \\
\hline $\begin{array}{l}\text { Regression analysis path a: } \\
\text { To predict Motivation to Learn by Lack of } \\
\text { Intimacy }\end{array}$ & .17 & $.03^{* *}$ & & $-.17^{* *}$ \\
\hline $\begin{array}{l}\text { Regression analysis path c: } \\
\text { To predict Academic Performance by Lack of } \\
\text { Intimacy }\end{array}$ & .15 & $.02^{* *}$ & & $-.15^{* *}$ \\
\hline $\begin{array}{l}\text { Hierarchical analyses } \\
\text { Step 1: path b } \\
\text { To predict Academic Performance by Motivation } \\
\text { to Learn } \\
\text { Step 2: path c' } \\
\text { To predict Academic Performance by Lack of } \\
\text { Intimacy (mediated by Motivation to Learn) }\end{array}$ & .29 & $.07^{* * *}$ & .01 & $.25^{* * *}$ \\
\hline
\end{tabular}

Note $^{*}=p<.05 ;{ }^{* *}=p<.01 ;=\mathrm{p}^{* * *}<.001$

Table 4

Regression Analyses Predicting Academic Performance by Conflict with Friends mediated by Motivation to Learn

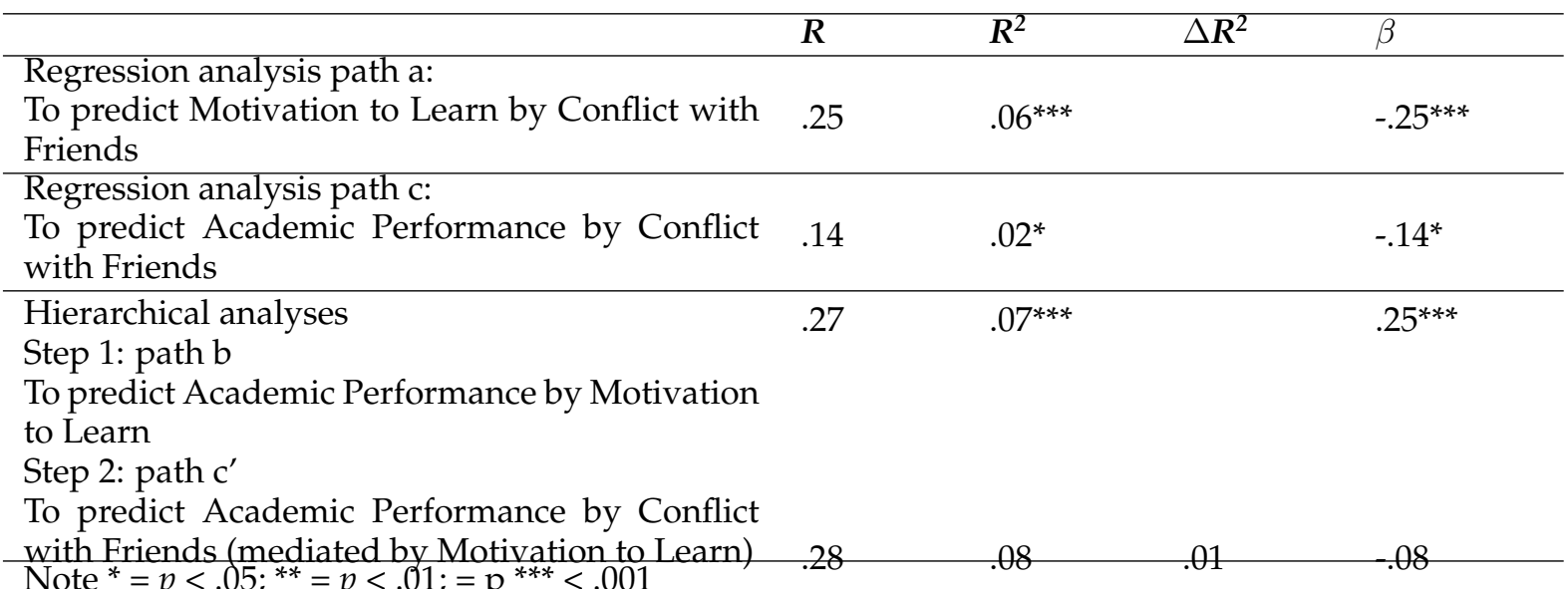




\section{Shanti, et al || Friends' Support}

In Table 5, 6, and 7, we presented the results concerning the mediating role of emotional adjustment between the three friend factors (friendship quality, lack of intimacy, and conflict with friends) and academic performance by again examining the four Baron and Kenny's conditions that have to be met to conclude to a mediating effect. From Table 5, 6, and 7, it is clear that when emotional adjustment was entered in the regression equation, the standardized regression coefficient of friendship quality on academic performance was reduced from $.16^{* *}$ to .08 (see Table 5), the standardized regression coefficient of lack of intimacy on academic performance from -.15** to -.06 (see Table 6), and the standardized regression coefficient of conflict with friends on academic performance from $-.14^{*}$ to -.04 (see Table 7).

We found evidence of a significant full mediation of emotional adjustment based on the Sobel tests for the relationship between friendship quality and academic performance $(t=2.60 ; p<.01)$, lack of intimacy and academic performance $(\mathrm{t}=2.71 ; p<.01)$, and for the relationship between conflict with friends and academic performance $(\mathrm{t}=2.91 ; p<.05)$.

Table 5

Regression Analyses Predicting Academic Performance by Friendship Quality mediated by Emotional Adjustment

\begin{tabular}{|c|c|c|c|c|}
\hline & $\boldsymbol{R}$ & $R^{2}$ & $\Delta R^{2}$ & $\beta$ \\
\hline $\begin{array}{l}\text { Regression analysis path a: } \\
\text { To predict Emotional Adjustment by Friendship } \\
\text { Quality }\end{array}$ & .47 & $.03^{* *}$ & & $.47^{* * *}$ \\
\hline $\begin{array}{l}\text { Regression analysis path c: } \\
\text { To predict Academic Performance by Friendship } \\
\text { Quality }\end{array}$ & .16 & $.22^{* * *}$ & & $.16^{* *}$ \\
\hline $\begin{array}{l}\text { Hierarchical analyses } \\
\text { Step 1: path b } \\
\text { To predict Academic Performance by Emotional } \\
\text { Adjustment } \\
\text { Step 2: path c' } \\
\text { To predict Academic Performance by Friendship }\end{array}$ & .21 & $.04^{* * *}$ & & $.17^{* *}$ \\
\hline Quality (mediated by Emotional Adjustment) & .22 & .05 & .01 & .08 \\
\hline
\end{tabular}

Note $^{*}=p<.05 ;{ }^{* *}=p<.01 ;=\mathrm{p}^{* * *}<.001$

Table 6

Regression Analyses Predicting Academic Performance by Lack of Intimacy mediated by Emotional Adjustment

\begin{tabular}{|c|c|c|c|c|}
\hline & $\boldsymbol{R}$ & $R^{2}$ & $\Delta R^{2}$ & $\beta$ \\
\hline Regression analysis path a: & & \multirow{2}{*}{\multicolumn{2}{|c|}{$.27^{* * *}$}} & \multirow[b]{2}{*}{$-.52^{* * *}$} \\
\hline $\begin{array}{l}\text { To predict Emotional Adjustment by Lack of } \\
\text { Intimacy }\end{array}$ & .52 & & & \\
\hline Regression analysis path c: & & \multirow{2}{*}{\multicolumn{2}{|c|}{$.02^{* *}$}} & \multirow[b]{2}{*}{$-.15^{* *}$} \\
\hline $\begin{array}{l}\text { To predict Academic Performance by Lack of } \\
\text { Intimacy }\end{array}$ & .15 & & & \\
\hline \multicolumn{4}{|l|}{ Hierarchical analyses } & \multirow{5}{*}{$.18^{* *}$} \\
\hline Step 1: path b & .21 & $.04^{* *}$ & & \\
\hline To predict Academic Performance by Emotional & & & & \\
\hline $\begin{array}{l}\text { Adjustment } \\
\text { Step 2: path } c^{\prime}\end{array}$ & & & & \\
\hline \multirow{2}{*}{$\begin{array}{l}\text { To predict Academic Performance by Lack of } \\
\text { Intimacy (mediated by Emotional Adjustment) }\end{array}$} & & & & \\
\hline & .21 & $.05^{* *}$ & .02 & -.06 \\
\hline
\end{tabular}


Continued from previous page

Note $^{*}=p<.05 ;{ }^{* *}=p<.01 ;=\mathrm{p}^{* * *}<.001$

Table 7

Regression Analyses Predicting Academic Performance by Conflict with Friends mediated by Emotional Adjustment

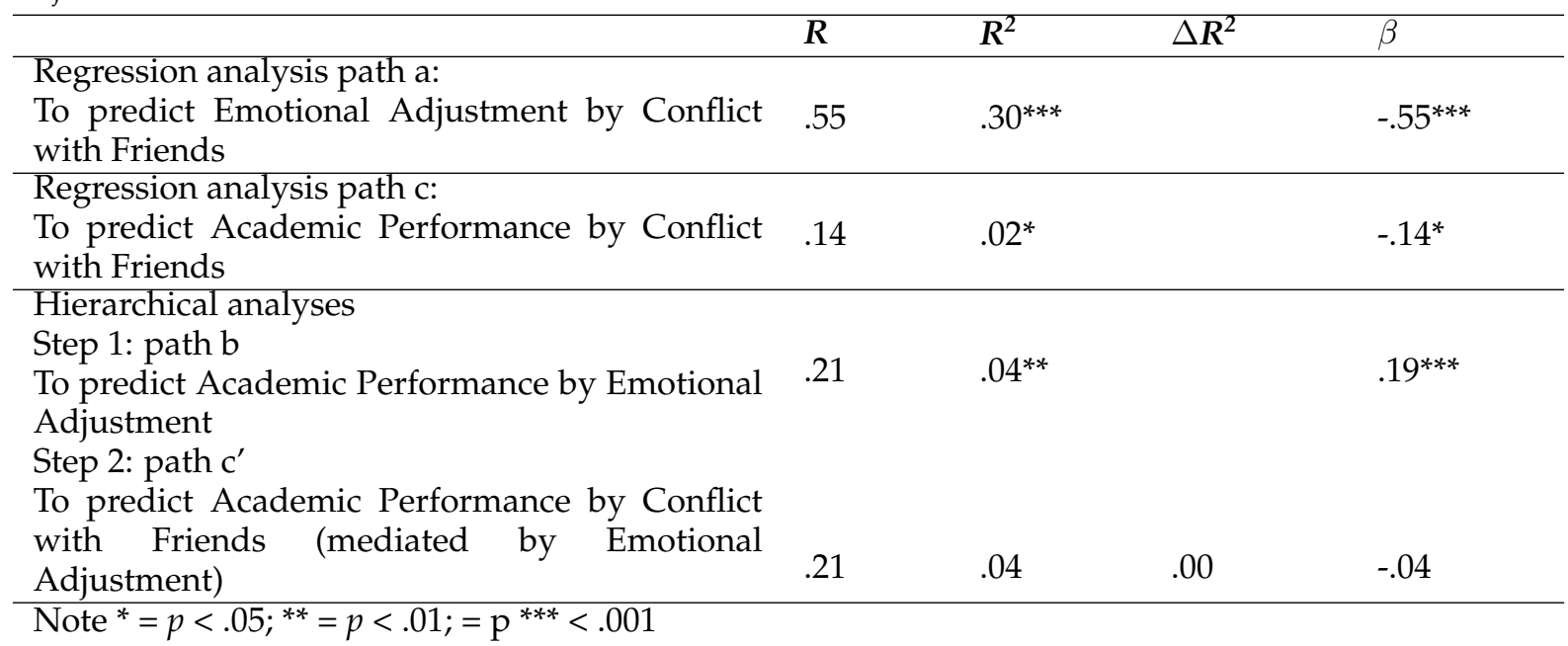

\section{Discussion}

Results show correlations between friendship quality and academic performance, lack of intimacy and academic performance, and conflict with friends and academic performance. The present study showeds that a good friendship quality was related to a good academic performance as well as a lack of intimacy with friends is related to a less good academic performance. It can be interpreted that first-year students must have friends who face the same challenges during adjustment to university because they know what their problems are. First-year students with a lack of intimacy have fewer opportunities to share problems with their friends and, thus, difficult to gain help they need to solve their problems, including problems related to achieving a high score on academic performance. The results confirmed previous studies that collaborated with mutual friends on academic tasks, such as working on homework together, group assignments, and sharing academic resources, might influence their academic performance (McGuire \& Leaper, 2016; Wentzel et al., 2018). These experiences enable students to disclose their thoughts and feelings to university, family, or each other, which may enhance their connectedness (wahyu ariani, 2017) to discuss about solving their problems together, academically and non-academically.

I also confirmed the hypothesis on a negative correlation between conflict with friends and academic performance. Conflict with friends was measured by items that expressed the negative impact of conflict with friends. Kim et al. (2019) explained that conflicts with friends are related to poor academic performance and adjustment. A possible explanation for the negative correlation between conflict with friends and academic performance is that conflicts do not correspond to the collectivist culture in which $\mathrm{X}$ university is located. The students are experienced difficulty to maintain harmony and social connectedness with their friends (wahyu ariani, 2017). This situation implies a lack of opportunity to open up with friends and discuss the struggles and demands in their first year, and this lack of opportunity predicts their poor academic performance.

Another possible explanation is that conflicts with friends influence them not to disclose their difficulties to their friends, which prevents them from getting support from their friends for their academic performance. Previous studies confirmed this explanation: during the conflict, they tend 


\section{Shanti, et al || Friends' Support}

to use hostile conflict resolution, withdrawal, and non-compliance (R. Yu et al., 2014), and dominate each other (Filsecker et al., 2020).

The present study showed a positive relationship between friendship quality and motivation to learn. A possible explanation is that following the previous study, having supportive friends is related to their belief that they may solve the problems, and as a consequence, they exert more effort in learning activities and prioritize learning activities (Wentzel et al., 2018). This study also confirmed a previous study that explores the motivation for learning of students from collectivistic cultures. wahyu ariani (2017) found that high-quality social relationships can create a secure environment for students from collectivistic cultures, enhancing their motivation for learning.

This study further revealed a negative relationship between lack of intimacy and motivation to learn and between conflict with friends and motivation to learn. These relationships mean that students with a lack of intimacy and who have had conflicts with friends lacked the motivation to learn. The reason for these results might be that lack of intimacy and conflict with friends reduce their class attendance (Kassarnig et al., 2018) and diminish the opportunities to ask their friends for help when they have problems (wahyu ariani, 2017; Wentzel et al., 2018). This situation directs leads them to feel hopeless when they have problems or feel incapable of dealing with day-to-day obstacles (Datu \& Yang, 2019; S. Yu \& Levesque-Bristol, 2018) and in turn causes them to have less energy and time to deal with the problems, which decreases their motivation to pursue academic goals (wahyu ariani, 2017).

A positive correlation was found between friendship quality and emotional adjustment, and a negative relationship was found between lack of intimacy and emotional adjustment, as well as between conflict with friends and emotional adjustment. A possible explanation for these correlations is that a good friendship quality is related to the intervention provided by friends (Iş1k \& Erguner-Tekinalp, 2017), such as support. The support may lessen stress and anxiety and helps them to overcome problems and to better adjust to university life.

The present study revealed that motivation to learn mediated the relation between friendship quality and academic performance. It appeared that students who perceived more friendship quality achieved a better academic performance by manifesting a higher motivation to learn. In other words, the better the friendship quality the students perceive, the better their academic performance, as a result of their greater motivation to learn.

The present study also revealed that motivation to learn mediated the relation between lack of intimacy and academic performance as well as between conflict with friends and academic performance. These findings mean that those students who experienced less intimacy and those who had more conflicts with their friends achieved lower academic performance because of the lower motivation to learn. These findings provide evidence that motivation to learn is important among first-year students because a new and more determined learning style is needed at university compared to high school. Friendship quality is one of the factors that increase first-year students' motivation to learn (Datu \& Yang, 2019; wahyu ariani, 2017; S. Yu \& Levesque-Bristol, 2018), while lack of intimacy and conflict with friends undermine their motivation to learn, which in turn influences their academic performance.

The results also showed that emotional adjustment mediated the relation between friendship quality and academic performance, between lack of intimacy and academic performance, and between conflict with friends and academic performance. These results showed that students who perceived better friendship quality had a better academic performance by manifesting a healthier emotional adjustment. In contrast, students who lacked intimacy and experienced conflict with their friends were less adjusted emotionally, which in turn adversely affected their academic performance. These results provide evidence confirmed by a previous study (Iş1k \& Erguner-Tekinalp, 2017; Taniguchi, 2014) that supportive friends increase first-year students' emotional adjustment, which is important to alleviate the consequence of their stressful experiences, and in turn, improves their academic performance.

The findings that motivation to learn and emotional adjustment are mediators show that motivation to learn and emotional adjustment play a central role in predicting academic performance. The mechanisms between the atmosphere of relationship with friends, whether it is positive (friendship quality) or negative (lack of intimacy and conflict with friends), and motivation to learn and emotional adjustment are not clear yet. One explanation is that relationships with their friends give them a chance to disclose and exchange information, which has a significant effect on them, mainly because 


\section{Shanti, et al || Friends' Support}

the relationship between adolescence and their friends gives more influentialce than their relationship with their parents as they did in their previous developmental stage.

The benefit of disclosing and exchanging information that affects their motivation to learn they are include: information about their challenge, the support provided for them and how to access the support provided for them, goal orientation (Supervia et al., 2019), strategy to deal with challenge (F. Y. Yu et al., 2018), learning strategy (Tsai2020), reassurance to about their efficacy (Sharififard et al., 2020). Then, motivation to learn influences academic performance, as confirmed by previous studies (Bayoumy \& Alsayed, 2021; Sharififard et al., 2020).

Elmer et al. (2017) found correlation between emotional well-being and having more friends in their strong-tied network. They explained that interacting with other individuals can change one's thoughts, feelings, attitudes, or behaviors. Disclosing their stress and negative thoughts may help them cope (Sharififard et al., 2020). Mikrut et al. (2019) gave an additional explanation that emotional disclosure improves psychological adjustment, but only when it occurs within a receptive social environment, such as buffering effect of stress and mental illness (Havewala et al., 2019), how to manage the conflict (Keener et al., 2019), problem-solving for their conflict (Dost-Gozkan, 2019). Social interactions that discourage, limit, or modify another person's expression of thoughts and feelings will hinder emotional disclosure and related to more inadequate adjustment (Mikrut et al., 2019). Thus, it explains why the positive atmosphere created by friendship quality will increase their emotional adjustment learn while a hostile atmosphere created through lack of intimacy and conflict with friends will decrease their emotional adjustment, which in turn will affect their academic performance (Carmona-Halty et al., 2019).

This study has several contributions. The first contribution is that this study made conclusive evidence for a motivation to learn and emotional adjustment as mediators.

This evidence supports predictors of academic performance. This proof mechanism tells us that motivation to learn and emotional adjustment must be considered in predicting academic motivation. Furthermore, we also proved that positive and negative atmospheres of friendship influence motivation to learn and emotional adjustment.

The second contribution is the sample representing the representation population (the first-year students of University X) derived from random cluster sampling. Since its representations, University $X$ may focus on the mediators in optimizing their students' academic performance.

Beyond the contributions, this study also has some limitations. The first limitation is the detailed mechanism of the model. We realize that between variables themselves, for example, between friends' support and motivation to learn and between friends' support and emotional adjustment, we have to elaborate more deeply about the psychological mechanism to explain the relationship. The mechanism that we explained, such as using motivational beliefs, coping, their positive and negative consequence of friendship, based on theoretical assumptions and still need to be proof by research.

\section{Conclusion}

The present study has found a mediating role of emotional adjustment in the relationship between friendship characteristics and academic performance, which are important for in a collectivist culture. Universities need to give attention not only to the students' motivation but also to their emotions in improving their students' academic performance.

Results of this study have several implicationimplications. Given that the results of this study highlight the role of friends in academic performance among first-year students, we encourage universities to design a curriculum that involves collaboration among students in the learning process, such as organizing sessions to promote supportive collaboration among students to overcome challenges at the university.

The present study is was correlational. We could examine the model using longitudinal research in the future. The results of this study were based on information from students of one private university in Indonesia. Therefore, the possibility of generalizing the findings for use in other institutions may be limited. It would be interesting to examine our model in other universities in order to confirm its 


\section{Shanti, et al || Friends' Support}

applicability.

This study gathered retrospective and self-report information about the students' perception of friendship quality, lack of intimacy, and conflict with friends. Although the students' perception of their relationships with their friends has the most impact on their behavior, multiple assessments (from friends and students) would be a valuable addition in future research.

\section{Recommendation}

Future studies can add information from friends and results of observations of, for example, a conflict between students to strengthen the validity of the concepts used in this study.

In this study, we also measured academic performance at the end of the student's first year. We found that friends' support influenced academic performance, mediated by a motivation to learn and emotional adjustment. More researches are needed to measure academic performance during the consecutive years in its relationship with friendship quality, lack of intimacy with friends, and conflict with friends. These analyses will give us information about the role of friends' support in academic performance in consecutive years.

In explaining the theoretical relationship between friendship quality, lack of intimacy with friends, and conflict with friends on the one hand and motivation to learn, emotional adjustment, and academic performance, on the other hand, we need to elaborate on specific characteristics, such as motivational beliefs and coping. However, we did not examine these characteristics concerning friendship quality, intimacy with friends, conflict with friends, motivation to learn, emotional adjustment, or academic performance. Future research has to consider examining the mediating role of motivational beliefs, coping, disclose oneself, with verifying the relationships we found in more detail.

To study students' integration into higher education, we need to explore student interactions and interactions of students with other university members, such as lecturers and administration staff. It would be relevant to explore how the relationships among all university members collaborate to support students in achieving excellent academic performance. Despite Although the present study was conducted in a collectivist culture, the results reflect the nature of college students' friendships in a collectivist culture and individualistic culture (Kaur \& Noman, 2015; wahyu ariani, 2017). Future studies could explore how the differences in the expression of friends' support needed by each culture so that there are specifically designed interventions for first-year students for both cultures.

\section{Acknowledgment}

The authors would like to express our special thanks to Research Assistants who helped with data collection for this study. We also thank the lecturers who granted us permission to visit the classes and administered the questionnaires.

\section{Funding}

This research was funded by the Radboud University of Nijmegen and the Atma Jaya Catholic University of Indonesia under a partnership scheme. This paper is part of a dissertation that can be accessed in Radboud University Library.

\section{Author's contribution}

The first author built theoretical concepts, managing data collection, writing most part if the manuscripts, wrote some parts of discussion sections.

\section{Conflict of interests}

The authors declare that there is no conflict of interest in this research. 


\section{Shanti, et al || Friends' Support}

\section{Orcid ID}

Theresia Indira Shanti 0000-0001-7137-3427

J.M.A.M. Janssens 0000-0003-2085-2772

Bernadette Setiadi 0000-0001-7137-3427

\section{References}

Ahmed, W., Minnaert, A., van der Werf, G., \& Kuyper, H. (2008). Perceived social support and early adolescents' achievement: The mediational roles of motivational beliefs and emotions. Journal of Youth and Adolescence, 39(1), 36-46. https:/ / doi.org/10.1007/s10964-008-9367-7

BAN-PT. (2019). Peraturan BAN-PT no 05 tahun 2019 tentang instrumen akreditasi program studi. https: / /www.banpt.or.id/wp-content/uploads /2019/10/Peraturan-BAN-PT-No.-5-Tahun-2019Instrumen-APS-1.pdf

Baron, R. M., \& Kenny, D. A. (1986). The moderator-mediator variable distinction in social psychological research: Conceptual, strategic, and statistical considerations. Journal of Personality and Social Psychology, 51(6), 1173-1182. https: / / doi.org / 10.1037 / 0022-3514.51. 6.1173

Bayoumy, H. M. M., \& Alsayed, S. (2021). Investigating relationship of perceived learning engagement, motivation, and academic performance among nursing students: A multisite study. Advances in Medical Education and Practice, Volume 12, 351-369. https: / / doi.org/10.2147/amep.s272745

Bohlin, G., \& Hagekull, B. (2009). Socio-emotional development: From infancy to young adulthood. Scandinavian Journal of Psychology, 50(6), 592-601. https:/ / doi.org/10.1111/j.1467-9450.2009. 00787.x

Buote, V. M., Pancer, S. M., Pratt, M. W., Adams, G., Birnie-Lefcovitch, S., Polivy, J., \& Wintre, M. G. (2007). The importance of friends. Journal of Adolescent Research, 22(6), 665-689. https: / / doi. org /10.1177/0743558407306344

Carmona-Halty, M., Salanova, M., Llorens, S., \& Schaufeli, W. B. (2019). Linking positive emotions and academic performance: The mediated role of academic psychological capital and academic engagement. Current Psychology, 40(6), 2938-2947. https: / / doi . org / 10.1007 / s12144-01900227-8

Ciairano, S., Rabaglietti, E., Roggero, A., Bonino, S., \& Beyers, W. (2007). Patterns of adolescent friendships, psychological adjustment and antisocial behavior: The moderating role of family stress and friendship reciprocity. International Journal of Behavioral Development, 31(6), 539-548. https:/ / doi.org/10.1177/0165025407080573

Clark, M., \& Schroth, C. A. (2010). Examining relationships between academic motivation and personality among college students. Learning and Individual Differences, 20(1), 19-24. https: / / doi.org/10.1016/j.lindif.2009.10.002

Clifton, R. A., Perry, R. P., Stubbs, C. A., \& Roberts, L. W. (2004). Faculty environments, psychosocial dispositions, and the academic achievement of college students. Research in Higher Education, 45(8), 801-828. https: / /doi.org/10.1007/s11162-004-5950-2

Cole, M. S., Harris, S. G., \& Feild, H. S. (2004). Stages of learning motivation: Development and validation of a measure1. Journal of Applied Social Psychology, 34(7), 1421-1456. https: / / doi. org/10.1111/j.1559-1816.2004.tb02013.x

Conti, R. (2000). Social Psychology of Education, 4(2), 189-211. https:/ / doi.org/10.1023/a:1009607907509

Crawford, J. R., \& Henry, J. D. (2003). The depression anxiety stress scales (DASS): Normative data and latent structure in a large non-clinical sample. British Journal of Clinical Psychology, 42(2), 111-131. https: / / doi.org/10.1348/014466503321903544

Datu, J. A. D., \& Yang, W. (2019). Academic buoyancy, academic motivation, and academic achievement among filipino high school students. Current Psychology, 40(8), 3958-3965. https://doi.org/10. 1007/s12144-019-00358-y

Demaray, M. K., Malecki, C. K., Davidson, L. M., Hodgson, K. K., \& Rebus, P. J. (2005). The relationship between social support and student adjustment: A longitudinal analysis. Psychology in the Schools, 42(7), 691-706. https:/ / doi.org/10.1002/pits.20120 


\section{Shanti, et al || Friends' Support}

Dost-Gozkan, A. (2019). Adolescents' conflict resolution with their parents and best friends: Links to life satisfaction. Journal of Child and Family Studies, 28(10), 2854-2866. https:/ / doi.org/10.1007/ s10826-019-01465-x

Elmer, T., Boda, Z., \& Stadtfeld, C. (2017). The co-evolution of emotional well-being with weak and strong friendship ties. Network Science, 5(3), 278-307. https://doi.org/10.1017/nws.2017.20

Filsecker, M., Abs, H. J., \& Roczen, N. (2020). The structure of conflict styles in adolescents. European Journal of Psychological Assessment, 36(4), 525-536. https:/ / doi.org/10.1027/1015-5759/a000527

Friedlander, L. J., Reid, G. J., Shupak, N., \& Cribbie, R. (2007). Social support, self-esteem, and stress as predictors of adjustment to university among first-year undergraduates. Journal of College Student Development, 48, 259-274. https:/ / doi.org/10.1353/CSD.2007.0024

Haber, A., \& Runyon, R. (1984). Psychology of adjustment. The Dorsey Press.

Havewala, M., Felton, J. W., \& Lejuez, C. W. (2019). Friendship quality moderates the relation between maternal anxiety and trajectories of adolescent internalizing symptoms. Journal of Psychopathology and Behavioral Assessment 2019 41:3, 41, 495-506. https: / / doi.org / 10.1007 / S10862-019-09742-1

Işık, Ş., \& Erguner-Tekinalp, B. (2017). The effects of gratitude journaling on turkish first year college students' college adjustment, life satisfaction and positive affect. International Journal for the Advancement of Counselling, 39. https:/ / doi.org/10.1007/s10447-017-9289-8

Kassarnig, V., Mones, E., Bjerre-Nielsen, A., Sapiezynski, P., Dreyer Lassen, D., \& Lehmann, S. (2018). Academic performance and behavioral patterns. EPJ Data Science, 7(1). https: / / doi.org / 10. 1140/epjds/s13688-018-0138-8

Kaur, A., \& Noman, M. (2015). Exploring classroom practices in collectivist cultures through the lens of hofstede's model. The Qualitative Report, 20, 1794-1811. https:/ / doi.org/10.1080/13603116. 2015.1090489

Keener, E., Strough, J., \& DiDonato, L. (2019). Adolescents' endorsement of communal and agentic conflict-management strategies with friends and romantic partners. Sex Roles 2018 80:9, 80, 578-585. https://doi.org/10.1007/S11199-018-0961-1

Kim, M.-H., Min, S., Ahn, J.-S., An, C., \& Lee, J. (2019). Association between high adolescent smartphone use and academic impairment, conflicts with family members or friends, and suicide attempts. PLOS ONE, 14, e0219831. https://doi.org/10.1371/journal.pone.0219831

Linden-Andersen, S., Markiewicz, D., \& Doyle, A. B. (2008). Perceived similarity among adolescent friends: The role of reciprocity, friendship quality, and gender. Journal of Early Adolescence, 29, 617-637. https:/ /doi.org/10.1177/0272431608324372

Lovibond, P. F., \& Lovibond, S. H. (1995). The structure of negative emotional states: Comparison of the depression anxiety stress scales (dass) with the beck depression and anxiety inventories. Behaviour Research and Therapy, 33, 335-343. https://doi.org/10.1016/0005-7967(94)00075-U

Major, D. A., Turner, J. E., \& Fletcher, T. D. (2006). Linking proactive personality and the big five to motivation to learn and development activity. Journal of Applied Psychology, 91, 927-935. https: //doi.org/10.1037/0021-9010.91.4.927

Markus, H. R., \& Kitayama, S. (1991). Culture and the self: Implications for cognition, emotion, and motivation. Psychological Review, 98, 224-253. https: / / doi.org/10.1037/0033-295X.98.2.224

McGuire, J. E., \& Leaper, C. (2016). Competition, coping, and closeness in young heterosexual adults' same-gender friendships. Sex Roles, 74(9-10), 422-435. https: / / doi.org / 10.1007 / s11199-0150570-1

Mikrut, E. E., Panjwani, A. A., Cipollina, R., \& Revenson, T. A. (2019). Emotional adjustment among parents of adolescents and young adults with cancer: The influence of social constraints on cognitive processing and fear of recurrence. Journal of Behavioral Medicine, 43(2), 237-245. https: / /doi.org/10.1007/s10865-019-00072-x

Petersen, I.-h., Louw, J., \& Dumont, K. (2009). Adjustment to university and academic performance among disadvantaged students in south africa. Educational Psychology, 29(1), 99-115. https: / / doi.org/10.1080/01443410802521066

Ramsay, S., Jones, E., \& Barker, M. (2007). Relationship between adjustment and support types: Youngand mature-aged local and international first year university students. Higher Education, 54, 247-265. https:/ / doi.org/10.1007/s10734-006-9001-0 


\section{Shanti, et al || Friends' Support}

Rey, L., Extremera, N., Durán, A., \& Ortiz-Tallo, M. (2013). Subjective quality of life of people with intellectual disabilities: The role of emotional competence on their subjective well-being. Journal of Applied Research in Intellectual Disabilities, 26, 146-156. https: / / doi.org / 10.1111/ JAR.12015

Rodriguez, N., Mira, C. B., Myers, H. F., Morris, J. K., \& Cardoza, D. (2003). Family or friends: Who plays a greater supportive role for latino college students? Cultural Diversity and Ethnic Minority Psychology, 9(3), 236-250. https://doi.org/10.1037/1099-9809.9.3.236

Ryan, A. M. (2001). The peer group as a context for the development of young adolescent motivation and achievement. Child Development, 72(4), 1135-1150. https: / / doi.org / 10.1111/1467-8624. 00338

Schneider, B. H., Tomada, G., Normand, S., Tonci, E., \& de Domini, P. (2008). Social support as a predictor of school bonding and academic motivation following the transition to italian middle school. Journal of Social and Personal Relationships, 25(2), 287-310. https: / / doi.org / 10.1177 / 0265407507087960

Sharififard, F., Asayesh, H., Hosseini, M. H. M., \& Sepahvandi, M. (2020). Motivation, self-efficacy, stress, and academic performance correlation with academic burnout among nursing students. Journal of Nursing and Midwifery Sciences, 7(2), 88. https:/ /doi.org/10.4103/jnms.jnms_30_19

Supervia, P. U., Bordas, C. S., \& Teruel, P. (2019). School motivation, goal orientation and academic performance in secondary education students. Psychology Research and Behavior Management, Volume 12, 877-887. https: / / doi.org/10.2147/prbm.s215641

Swenson, L. M., Nordstrom, A., \& Hiester, M. (2008). The role of peer relationships in adjustment to college. Journal of College Student Development, 49(6), 551-567. https: / / doi.org/10.1353/csd.0. 0038

Taniguchi, H. (2014). Interpersonal mattering in friendship as a predictor of happiness in japan: The case of tokyoites. Journal of Happiness Studies, 16(6), 1475-1491. https: / / doi.org / 10.1007 / s10902-014-9570-z

Tucker, C. M., Zayco, R. A., Herman, K. C., Reinke, W. M., Trujillo, M., Carraway, K., Wallack, C., \& Ivery, P. D. (2002). Teacher and child variables as predictors of academic engagement among low-income african american children. Psychology in the Schools, 39(4), 477-488. https: / / doi. org/10.1002/pits.10038

van Rooij, E. C. M., Jansen, E. P. W. A., \& van de Grift, W. J. C. M. (2018). Correction to: First-year university students' academic success: The importance of academic adjustment. European Journal of Psychology of Education, 33(4), 769-769. https:/ / doi.org/10.1007/s10212-017-0364-7

Vermunt, J. D. (2005). Relations between student learning patterns and personal and contextual factors and academic performance. Higher Education, 49(3), 205-234. https:/ / doi.org/10.1007/s10734004-6664-2

wahyu ariani, D. (2017). Do social relationship affects motivation? Advances in Management and Applied Economics, 7.

Wentzel, K. R., Jablansky, S., \& Scalise, N. R. (2018). Do friendships afford academic benefits? a meta-analytic study. Educational Psychology Review, 30(4), 1241-1267. https: / / doi . org / 10. 1007/s10648-018-9447-5

Wilson, I., \& Madsen, S. R. (2008). The influence of maslow's humanistic views on an employee's motivation to learn. Journal of Applied Management and Entrepreneurship, 13, 46-62. https : / / www . proquest . com / scholarly - journals / influence - maslows - humanistic - views - on employees/docview / 203897252 /se-2?accountid=48149

Wongtongkam, N. (2019). Influence of coping, self-esteem and social support on undergraduate students' emotional distress. Health Education, 119(3), 187-201. https: / / doi.org / 10.1108/he01-2019-0001

Yazedjian, A., Toews, M. L., \& Navarro, A. (2009). Exploring parental factors, adjustment, and academic achievement among white and hispanic college students. Journal of College Student Development, 50(4), 458-467. https:/ / doi.org/10.1353/csd.0.0080

Yu, F. Y., Wu, W. S., \& Huang, H. C. (2018). Promoting middle school students' learning motivation and academic emotions via student-created feedback for online student-created multiple-choice 


\section{Shanti, et al || Friends' Support}

questions. Asia-Pacific Education Researcher, 27, 395-408. https:/ / doi.org/10.1007/s40299-0180398-x

Yu, R., Branje, S. J. T., Keijsers, L., \& Meeus, W. H. J. (2014). Personality types and development of adolescents' conflict with friends. European Journal of Personality, 28(2), 156-167. https: / / doi. org/10.1002/per.1913

Yu, S., \& Levesque-Bristol, C. (2018). Are students in some college majors more self-determined in their studies than others? Motivation and Emotion, 42(6), 831-851. https://doi.org/10.1007/s11031018-9711-5 